\title{
MUJER Y TRABAJO: ESTUDIO DE CASO DE LA SITUACIÓN LABORAL Y POLÍTICA DE LAS MUJERES EN LAS ADMINISTRACIONES LOCALES DE LA PROVINCIA DE CÓRDOBA
}

\author{
María Verónica Luetto* \\ María Marta Santillán Pizarro**
}

\begin{abstract}
Resumen: El trabajo, con técnicas cuantitativas, indaga acerca del estado de situación laboral de las mujeres en las administraciones públicas locales de la provincia de Córdoba, su participación política, sus roles de liderazgo y toma de decisiones. Se concluye que, en sintonía con otros estudios, se está avanzando en términos cuantitativos en la participación de mujeres en la administración pública. Sin embargo, la realidad pone de relieve que esta institución continúa siendo patriarcal y que en ella existen techos y muros de cristal que dificultan la participación de las mujeres en roles jerárquicos y de toma de decisiones.
\end{abstract}

Palabras claves: gobiernos locales; participación de mujeres; segregación ocupacional; precariedad laboral.

Mulheres e trabalho: um estudo de caso da situação laboral e política das mulheres na administração local da Província de Córdoba (AR)

Resumo: O trabalho foi desenvolvido a partir de técnicas qualitativas e indaga sobre a situação laboral das mulheres na administração públicas na Provincia de Córdoba - Argentina - sobre sua participação política e seu papel de liderança na tomada de decisões. Conclui-se, juntamente com outros estudos, que tem se avançado em termos qualitativos na participação das mulheres na administração pública. Entretanto, a realidade ainda indica que a instituição política continua sendo patriarcal existindo

\footnotetext{
* Facultad de Ciencias Económicas y Administración UCC, Universidad Catolica de Cordoba. veronica.luetto@gmail.com.

** Asociación Civil Clínica Jurídica de Interés Público, Universidad Catolica de Cordoba.
}

Recebido em: 31/11/2015 - Aceito em: 30/04/2016. 
muitos obstáculos que dificultam a participação das mulheres nos papéis hierárquicos de tomada de decisão.

Palavras-chave: Governo locais; participação de mulheres; segregação ocupacional; precariedade laboral.

Woman and work. a case study about labor and political situation of women in local government in the Province of Córdoba

\begin{abstract}
The article, through quantitative research techniques, inquiries about the status of the employment situation of women in local government in the province of Cordoba, in addition to their political participation, leadership roles and decision making. It concludes that in recent years there has been progress in quantitative terms in the participation of women in public administration. However, reality shows that this institution remains a patriarchal system where there are ceilings and glass walls that hinder the participation of hierarchical and women in decision-making roles.
\end{abstract}

Keywords: local government; participation of women; occupational segregation; job insecurity.

\title{
1 - Introducción
}

En las últimas décadas se ha comenzado a reconocer las desigualdades y vulneraciones de derechos que sufren las mujeres, basados principalmente en el género.

Desde los Estados, una de las principales acciones asumidas para garantizar y promover la igualdad entre varones y mujeres, ha sido el desarrollo de marcos normativos y jurídicos. Especialmente en Argentina, los avances en el reconocimiento y apropiación de la problemática han resultado muy significativos en relación a la adhesión de normativas internacionales y su adecuación a las propuestas e iniciativas impulsadas para lograr la igualdad de oportunidades en diversos ámbitos. Sin embargo y tal como afirma Pautassi (2001: 280) el "reconocimiento de la igualdad entre los sexos fue quedando anclado a garantías de igualdad formal con escasos avances en materia de igualdad material".

Entre las distintas dimensiones comprendidas por los derechos de las mujeres, el ámbito laboral constituye uno de los pilares fundamentales dada la inmanente vinculación de la mujer 
con el desarrollo. Si consideramos que las diferencias de género se producen, mantienen y reproducen en los ámbitos simbólicos del lenguaje y la cultura, las mismas cobran especial relevancia en materia laboral. La persistencia de inequidades colabora en sostener situaciones que vulneran el ejercicio real y efectivo de los derechos de las mujeres, conforme a los cambios evidenciados en las últimas décadas. Esta situación resulta más acuciante en los ámbitos urbanos donde cada vez hay mayor proporción de mujeres en trabajos productivos, por lo que debería existir una redefinición de los roles preasignados de varones y mujeres (Famá, 2011: 23). Además, múltiples trabajos en Argentina han evidenciado la existencia de desigualdades en el mercado laboral, tales como segregación ocupacional vertical y horizontal, en diferentes ámbitos laborales (Barrancos, 2007; Pautassi, 2001; Burijovich, J y Laura Pautassi, 2005, Rojo Brizuela y Tumini, 2008).

En este contexto, el trabajo propone detectar posibles brechas de género en las administraciones públicas locales de la Provincia de Córdoba. Se analizan diferencias en relación a las oportunidades en la participación política, la participación en roles de toma de decisiones, la existencia de áreas específicas para mujeres y los modos de contratación.

Es importante señalar que Argentina adopta la forma federal de gobierno por lo cual las provincias son autónomas, y de acuerdo a los artículos 5 y 123 de la Constitución Nacional los municipios también son autónomos, es decir, unidades políticas que pueden elegir sus propias autoridades y dictar sus propias normas. En relación con datos socio- demográficos, y de acuerdo al censo nacional de $2010^{1}$ Córdoba es una provincia con una población total de 3.308.876 habitantes, de los cuales el 51,5\% de la población son mujeres. Esta provincia tiene la particularidad de que las mujeres alcanzan mayor nivel educativo: por ejemplo $9 \%$ de ellas tiene estudios terciarios y 2,9\% estudios universitarios,

\footnotetext{
${ }^{1}$ Los datos censales para las provincia de Córdoba se encuentran disponibles en http://www.indec.gov.ar/nivel4_default.asp?id_tema_1=2\&id_tema2=41\&id_ tema_3=135.
} 
en cambio un $4 \%$ y un $2,2 \%$ de los varones alcanza dichos niveles educativos, respectivamente. Estos mayores logros educativos de las mujeres no se ven reflejados en la inserción laboral ya que ellas presentan una mayor tasa de desocupación que los varones. Según datos del mismo censo, un $8,5 \%$ de mujeres se encuentra desocupada, mientras que un $3,8 \%$ de varones asume la misma condición.

Respecto al sector de inserción laboral, de las mujeres que trabajan, el $28 \%$ se encuentra en el sector público, en comparación a un $20 \%$ de varones en el mismo sector. Por otra parte, del total de empleados del sector público casi un $52 \%$ son mujeres. A pesar de que, como se dijo en el párrafo precedente, las mujeres en la provincia alcanzan mayores niveles educativos, al interior del estado la situación se invierte: de las empleadas mujeres, un $8 \%$ presenta estudios terciarios y un $15 \%$ universitarios. En tanto entre los varones un 25\% tiene estudios terciarios y un $26,2 \%$ universitarios.

Partiendo de estos datos socio-demográficos se decidió estudiar la situación de las mujeres en los municipios de la provincia de Córdoba debido a dos motivos fundamentales, a saber: a. de acuerdo a un estudio de Archenti y Albaine (2012) Córdoba era una de las provincias con mayor cantidad de mujeres intendentas al año 2011 (sólo tres provincias la superaban en este punto) pero la situación a nivel del poder legislativo local era la contraria, ya que estudiada la capital de la provincia, se observaba en el mismo estudio que Córdoba Capital era una de las ciudades con menor participación de mujeres en el Concejo Deliberante (denominación que toma el Poder Legislativo en el ámbito municipal), de manera que resultaba interesante observar cuál era la situación actual en la provincia, tanto a nivel de cargos de toma de decisiones como a nivel de estabilidad laboral; y b. desde el año 2008 en la provincia de Córdoba se comenzaron a implementar políticas públicas de mujeres y de género, entre las cuales puede mencionarse "Córdoba con ellas" (decreto provincial 699 del 18/5/2010), política pública provincial que tenía como objetivo la promoción del desarrollo, la inserción social y laboral de las mujeres, contando con un núcleo 
destinado a la temática de mujer y trabajo, de manera que resultaba oportuno observar si estas políticas tenían repercusión o no en los municipios de la provincia, especialmente, en su propio ámbito laboral.

En los acápites siguientes se presentará el marco teórico y metodológico, para luego presentar los resultados a través del mapa de género en 17 municipios $^{2}$ de la provincia de Córdoba, la participación política de las mujeres y las segregaciones ocupacionales (verticales y horizontales) existentes. Posteriormente, se plantea una discusión teórica relativa a la importancia del municipio y su rol en la construcción de la ciudadanía, y especialmente, de la ciudadanía de las mujeres, y las primeras conclusiones alcanzadas en este trabajo de investigación.

\section{2 - Marco teórico y antecedentes}

A los fines de desarrollar el estudio de las brechas de género o inequidades de género en el ámbito de las administraciones locales, es necesario definir términos tales como: brechas de género, participación política, segregaciones ocupacionales.

Eneste trabajo se comprendelas brechas degéneroenel mismo sentido que inequidades de género, e indica las desigualdades entre hombres y mujeres en el mercado de trabajo (Abramo y Valenzuela, 2006: 30), donde el progreso laboral de las mujeres no supone necesariamente el aumento de sus oportunidades de encontrar una ocupación que cumpla con condiciones mínimas de calidad ((Abramo y Valenzuela, 2006: 31).Siguiendo los aportes de Esquivel (2007: 366, citado en Rojo Brizuela y Tumini, 2008: 57):

\footnotetext{
${ }^{2}$ Los municipios que respondieron la encuesta son: A. Municipios con más de 10.000 habitantes: Arroyito, Carlos Paz, Corral de Bustos, Cruz del Eje, Deán Funes, General Cabrera, Jesús María La Falda, Marcos Juárez, Oliva, Río Segundo y Río Cuarto; B. Municipios con menos de 10.000 habitantes: Buchardo, Camilo Aldao, Justiniano Posse, Monte Buey y Tancacha.
} 
la discriminación en el mercado de trabajo se refiere a una situación en la que dos personas, igualmente productivas en el sentido material y físico, son tratadas de manera diferente (una de ellas peor) sólo en virtud de características observables como su género. Dicho tratamiento diferencial se expresa tanto en niveles salariales diferentes para individuos comparables (el resultado observable de la discriminación) como en diferentes demandas para sus servicios del trabajo al salario dado, es decir, en segregación.

La participación política de las mujeres se refiere a la vinculación de las mujeres y la política y, específicamente a la ocupación de puestos de poder en la esfera política (Fernández Poncela, 2006: 117).

Y finalmente, la segregación ocupacional implica la concentración de las mujeres en cargos no jerárquicos (segregación vertical) $y$ en trabajos rotulados como femeninos: servicio doméstico, enseñanza, cuidado de la salud, etc. (segregación horizontal) (PNUD, 2011: 19 y ss.).

En cuanto a los antecedentes, diversos estudios e investigaciones corroboran que el mapa de género en el ámbito laboral es discriminatorio. A modo de ejemplo, las mujeres representan el $51 \%$ de la población mundial, y ocupan menos del 10\% de los cargos directivos (Corona Godínez et al, 2002: 14). En el caso de Argentina, las investigaciones de Barrancos (2007); Rojo Brizuela y Tumini (2008) aportan evidencias referidas a que la incorporación de las mujeres en el mercado de trabajo en Argentina se remonta a los sesenta, principalmente vinculada a los avances en el acceso a mayores niveles educativos. Continúa incrementándose en décadas posteriores, y en los noventa se acelera el proceso en contextos de aumento de desempleo y deterioro de los salarios reales de los jefes varones. Después de los 90 la situación se estabiliza. Las autoras afirman que en 2007 se observa un mercado de trabajo con elevada inequidad de género, en el que las mujeres presentan una menor participación en el mercado de trabajo, 
mayores tasas de desempleo, y menor ingreso por hora trabajada (Barrancos, 2007; citado en Rojo Brizuela y Tumini, 2008).

La administración pública, en cuanto a la participación política y en cargos de decisiones de las mujeres ha sido objeto de estudio particular, y ha evidenciado una estructura fundada en valores, actitudes y prácticas patriarcales. Así PNUD (2014: 12) explica que se pueden observar "algunas cantidades absolutas alentadoras en la administración pública, pero no necesariamente en los puestos de mayor influencia o en todos los sectores de forma uniforme".

Un informe de la Organización para la Cooperación y el Desarrollo Económico (2014: 96 y ss.), puso de manifiesto que en los países que constituyen la organización las mujeres representan casi el $50 \%$ de la fuerza laboral en los sectores públicos; sin embargo, ocupan categorías laborales más bajas, trabajan a tiempo parcial, sufren segregación ocupacional horizontal, brechas salariales (la brecha salarial de género en el sector público es más bajo para los trabajadores más jóvenes y es mayor en el extremo superior de la distribución del ingreso); además se observan brechas persistentes en el acceso a servicios de guardería y cuidado de los ancianos.

En el caso de América Latina se percibe una feminización de la política, ya que entre 1994 y 2004 la participación de la mujer “aumentó en promedio, de $9 \%$ a $14 \%$ en el poder ejecutivo (en posiciones ministeriales), de $5 \%$ a $13 \%$ en el senado y de $8 \%$ a 15 \% en la cámara baja o en parlamentos unicamerales" (Buvinic y Roza, 2004: 1)

En el ámbito específico de los espacios locales en Argentina, el proyecto ENMUNI de la asociación civil Manos Solidarias informaba que hasta octubre de 2007 sólo el 8\% de las intendencias en Argentina eran ocupadas por mujeres, y que el 84,33 \% de estos casos se correspondían a municipios con una población inferior a 5.000 habitantes. Las elecciones de octubre de 2007 elevó este número al $10 \%$.

Las investigaciones coinciden en la descripción de inequidades basadas en estereotipos de género y es por ello 
que resulta de importancia analizar lo que ocurre en los estados municipales.

\section{3 - Datos y metodología}

La recolección de la información se llevó a cabo a través de un formulario auto administrado que cada una de las administraciones públicas locales procedió a responder.

Con los datos obtenidos se procedió a realizar una lectura descriptiva en perspectiva comparada de la situación entre varones y mujeres.

A continuación se presentan los primeros resultados alcanzados que se relacionan fundamentalmente con los indicadores de brechas en el empleo público y en el desempeño de cargos funcionales de naturaleza política.

\section{4 - Resultados}

\section{1 - Mapa de género en las administraciones locales de la provincia de Córdoba: estudio de casos}

Ante todo cabe aclarar que todos los casos analizados se tratan de unidades políticas con el estatus jurídico de municipios. En la provincia de Córdoba el art. 181 de la Constitución Provincial ${ }^{3}$ y el art. 2 de la ley 8102 definen a los municipios como las poblaciones estables de más de dos mil (2.000) habitantes. En Argentina, por ser un estado federal, los municipios son considerados como el tercer nivel de gobierno, luego del estado nacional y de los estados

\footnotetext{
${ }^{3}$ Artículo 181 Constitución de la Provincia de Córdoba: “Toda población con asentamiento estable de más de dos mil habitantes, se considera Municipio. Aquellas a las que la ley reconozca el carácter de ciudades, pueden dictar sus Cartas Orgánicas". Según la ley 8102 son ciudades los asentamientos con más de 10.000 habitantes.
} 
provinciales, y además por mandato constitucional los municipios son unidades políticas autónomas (art. 123 de la Constitución Nacional) $)^{4}$.

Las administraciones públicas locales toman importancias en aras a la calidad de la democracia, porque por su cercanía con el ciudadano, con las problemáticas de los mismos, favorece la capacidad ciudadana de autogobierno; la participación social y el desarrollo de las libertades individuales (Escobar y Solari, 1996: 108). Es por estos motivos, que resulta trascendental conocer como los municipios reconocen y aceptan las diversidades, heterogeneidades y la equidad entre varones y mujeres en su interior.

El análisis de la cantidad total de empleados, no permite observar en términos cuantitativos diferencias significativas entre varones y mujeres. Así de un total de 3480 empleados, 1972 son varones $(56,7 \%)$ y 1508 mujeres (43,3\%) (Ver gráfico 1$)$.

\footnotetext{
${ }^{4}$ A modo informativo, cabe mencionar que Argentina es una estado federal, y de acuerdo a su Constitución los municipios son unidades políticas autónomas. Claramente el art. 123 establece que gozan de autonomía institucional, política, administrativa, económica y financiera, lo que denota que la Constitución Nacional les otorga una autonomía amplia. Para su comparación con la República Federativa del Brasil se recomienda la lectura del "Estudio comparativo de las leyes de régimen local en América Latina", disponible en http://www.parlatino.org/pdf/comisiones/politicos/exposiciones/xvi-estudiocomparativo-leyes-regimen-aruba-22-sept-2011.pdf.
} 
Gráfico 1 - Proporción de empleados de los municipios según género en 17 Municipios de la Provincia de Córdoba. Año 2015.

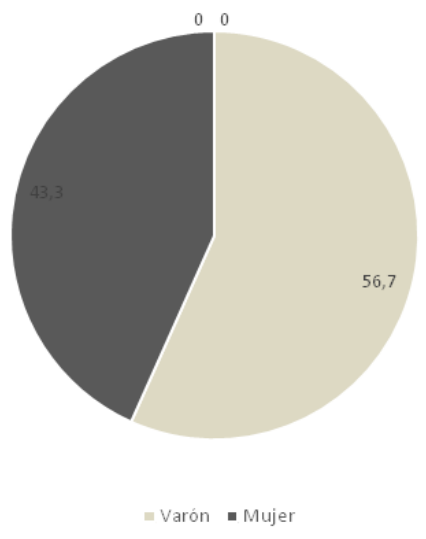

Elaboración propia.

Esta escasa diferencia marca una tendencia a la feminización del trabajo en las administraciones locales, sin que ello signifique por sí mismo la existencia de equidad de género, es por ello que resulta necesario indagar hacia el interior de las instituciones, para comprender si existe una real participación política y en la toma de decisiones por parte de las mujeres.

\section{2 - Participación política de las mujeres.}

En este apartado se analizará la participación de las mujeres en los poderes del Estado. Es así que en relación con el ejercicio del Poder Ejecutivo municipal, que se encuentra en cabeza de los denominados intendentes, de los 17 municipios estudiados, 13 cuentan con un intendente varón, y sólo 4 tienen una intendente mujer (Ver gráfico 2). 
La diferencia por género disminuye en la integración del Poder Legislativo local, denominado Concejo Deliberante. Así, en los 17 municipios analizados, existen 71 concejales varones (56,8 $\%)$ y 54 mujeres (43,2 \%) (ver gráfico 2 ).

En los municipios y comunas de Córdoba, existe un órgano de control de la hacienda pública, que se ha llamado Tribunal de Cuentas ${ }^{5}$, y cuyos integrantes son electos por el voto directo de la población. Estos organismos en los municipios estudiados se constituyen con 27 varones $(52,9 \%)$ y 24 mujeres $(47,1 \%$ ) (ver gráfico 2).

En lo relativo a la composición de los concejos deliberantes y de los tribunales de cuenta, cabe destacar que 10 de los municipios estudiados no cuentan con carta orgánica, y se rigen por la ley provincial 8901, denominada de cupo femenino, que establece en su art. 2 el principio de participación equitativa de los géneros, y en su art. 3 especifica que las listas de candidatos deben contener porcentajes equivalente de candidatos varones y mujeres, lo que explica la mayor paridad existente en los cargos de concejales y de integrantes de los tribunales de cuenta.

Finalmente, en los municipios con más de dos mil habitantes, y que no tienen sedes judiciales en su jurisdicción, de acuerdo a lo estatuido por el art. 45 de la ley orgánica del Poder Judicial de Córdoba, cuentan con jueces de paz, que por lo tanto, son parte del Poder Judicial provincial, pero se ubican en el éjido municipal ${ }^{6}$.

${ }^{5}$ Los tribunales de cuenta se encuentran establecidos en el marco de la Constitución de la Provincia de Córdoba, en la ley orgánica de municipios de la provincia de Córdoba, y es adoptado por las cartas orgánicas de los municipios. Los tribunales de cuentas son órganos de control externo de la hacienda pública, cuya función primordial es el control de la legalidad del gasto. El art. 83 de la Constitución de la provincia además establece que los municipios que dicten sus propias cartas orgánicas deben garantizar la existencia de un tribunal de cuentas (art. 183 inc. 3).

${ }^{6}$ El art. 1 de la ley orgánica del Poder Judicial de Córdoba (ley 8435) explica que "el Poder Judicial es ejercido por el Tribunal Superior de Justicia. También lo es por las Cámaras en lo Civil y Comercial, en lo Contencioso-Administrativo, en lo Criminal, de Acusación, de Menores, del Trabajo y de Familia y por los 
Cabe señalar que hasta el año 2010 los jueces de paz eran designados discrecionalmente por el poder ejecutivo provincial, $\mathrm{y}$ a partir de dicho año se instituyó el concurso como medio idóneo para la selección de estos jueces. En el caso de este cargo del Poder Judicial, la diferencia por género no es de importancia, ya que de 14 municipios que cuentan con este cargo, 8 son ejercidos por varones y 6 por mujeres (ver gráfico 2).

Gráfico 2 - Proporción de intendentes municipales, jueces de paz, concejales e integrantes del Tribunal de Cuentas, según género en 17 Municipios de la Provincia de Córdoba. Año 2015.

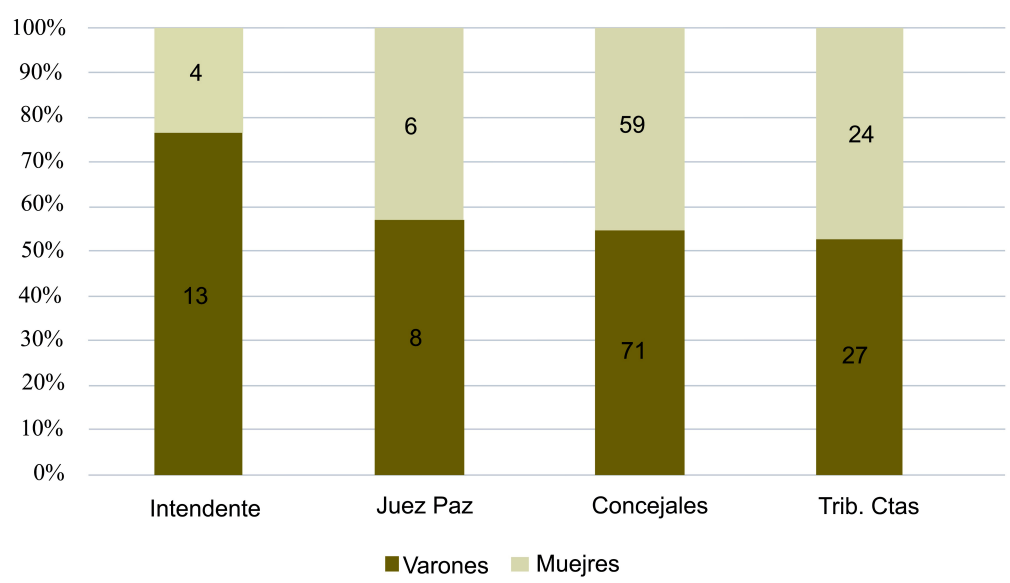

Elaboración propia.

Jueces en lo Civil y Comercial, de Control, Correccional, de Faltas, Electoral, de Familia, de Menores, de Conciliación, los reemplazantes y Conjueces que los sustituyan, y de Paz". 
Por otra parte, debe mencionarse que las diferencias en la participación política en el Poder Ejecutivo local parecen no disminuir a través del tiempo, ya que en las últimas elecciones populares desarrolladas en los municipios en estudio, existió una inmensa mayoría de candidatos varones para el cargo de intendente. A nivel del Poder Legislativo local y del organismo de control externo de la hacienda pública, también se mantiene la escasa diferencia por género, la cual se reitera, debe ser comprendida como consecuencia de la existencia de un cupo femenino del $50 \%$ establecido por ley.

En concreto, de 60 candidatos a intendentes en los 17 municipios, sólo 3 fueron candidatas mujeres; por su parte de los 644 candidatos a concejales, 267 fueron candidatas mujeres, y finalmente, de los 247 candidatos a tribunal de cuenta, 116 fueron mujeres (ver gráfico 3).

Gráfico 3 - Proporción de candidatos a intendente, concejales y tribunal de cuentas, según género en 17 Municipios de la Provincia de Córdoba. Año 2015.

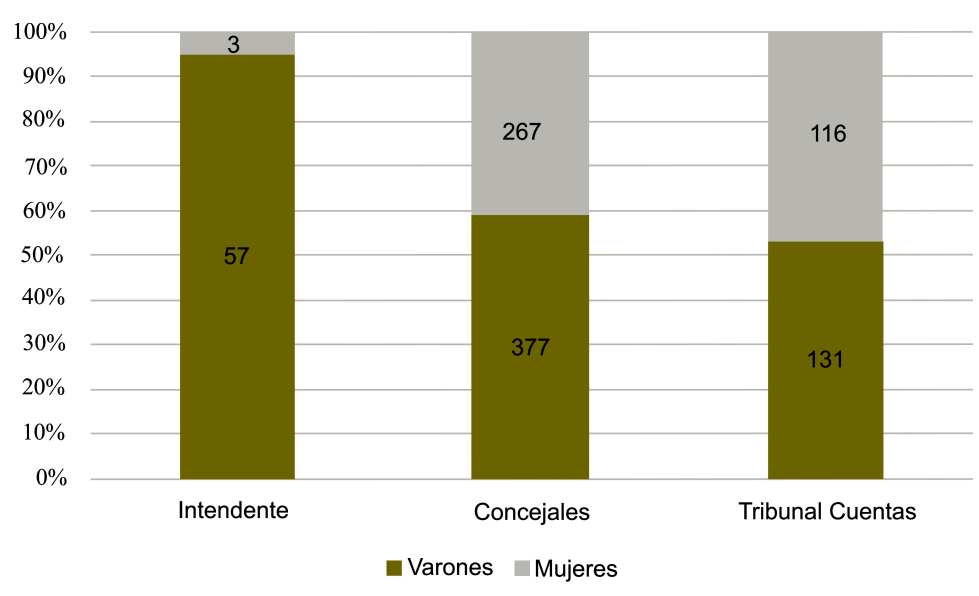

Elaboración propia. 


\section{3 - Segregaciones ocupacionales}

\subsection{1 - Segregación vertical: participación en roles de liderazgo y de toma de decisiones}

En los párrafos precedentes se pudo observar que en el cargo del poder ejecutivo hay una importante preeminencia de varones, y que la mayor equidad en los poderes legislativos locales y en los órganos de control se debe a la existencia de acciones afirmativas. La inequidad observada en la cabeza del poder ejecutivo, se reitera en los máximos niveles jerárquicos del municipio. Así de 213 cargos de funcionarios de máximo nivel, sólo 55 (25,8\%) son ocupados por mujeres, y de 105 cargos directivos, tan sólo 34 (32,4\%) están reservados para mujeres (ver gráfico 4 ). Estos datos evidencian claramente una subrepresentación de las mujeres en los espacios de poder y toma de decisiones.

Gráfico 4 - Proporción de cargos de funcionarios y directivos según género en 17 Municipios de la Provincia de Córdoba. Año 2015.

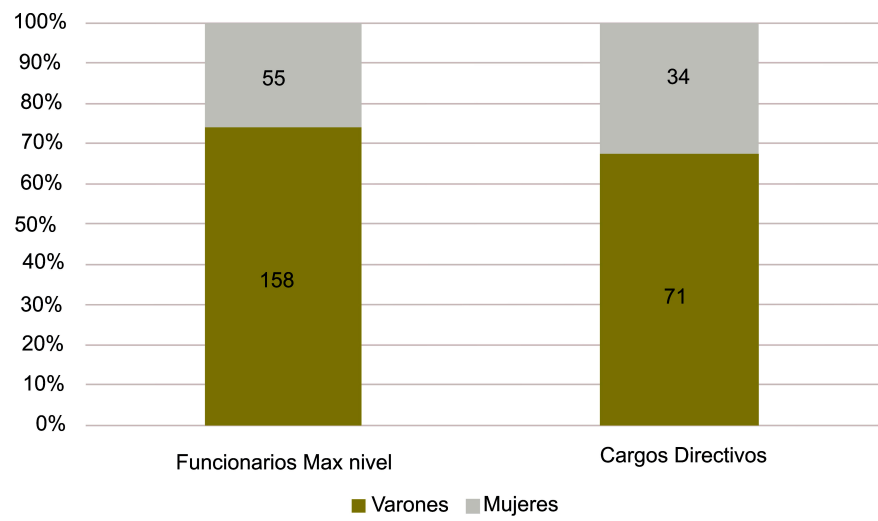

Elaboración propia. 
En este punto cabe referenciar los estudios de PNUD (2014) para América latina y el Caribe, que indican la existencia de una marcada feminización de la política en los espacios macros de los parlamentos nacionales, no ocurriendo lo mismo en las administraciones locales, y en los espacios de liderazgo y toma de decisiones. De manera que la mayor participación de las mujeres en el ámbito laboral de las administraciones públicas locales que surge del mapa de género, no significa un reconocimiento de un rol activo y fundamental de éstas, sino la simple ocupación de espacios o trabajos que se han desjerarquizado social y económicamente, y la mera expresión del ideal de igualdad y de superación respecto de la generación de mujeres anterior.

\subsection{2-Segregación horizontal: territorios masculinos y femeninos}

El análisis de los casos ha permitido identificar territorios masculinos y femeninos en la realidad de las administraciones públicas locales. En este sentido, en relación con áreas exclusivas para algunos de los géneros, pueden mencionarse como áreas típicas de varones: a Obras y servicios públicos (el 93,9\% de los cargos pertenecen a varones); b. Control o inspección (el 66,6 $\%$ de los puestos están ocupados por varones), y c. Economía y Finanzas (el 55,1 \% de los cargos pertenecen a varones), y como áreas mayormente femeninas: a. Desarrollo social (el 71,4 \% de los cargos son ocupados por mujeres) y b. educación (el 59,9 \% de los cargos corresponden a mujeres), c. salud (el 58,5 \% de los puestos pertenecen a mujeres). Cabe destacar que tanto desarrollo social como salud son áreas claramente vinculadas con la organización social del cuidado ${ }^{7}$, cuya responsabilidad central parece recaer

\footnotetext{
${ }^{7}$ Se entiende por organización social del cuidado "a la manera en que interrelacionadamente las familias, el Estado, el mercado y las organizaciones comunitarias, producen y distribuyen cuidado" (Rodríguez Enriquez y Pautassi, 2014: 11). Los estudios realizados en Argentina evidencian que la organización social del cuidado en este país es asumido mayormente por los hogares y, dentro de ellos, por las mujeres (Rodríguez Enriquez y Pautassi, 2014: 12).
} 
en las mujeres, o mejor dicho, son tareas atribuidas cultural y socialmente a las mujeres ${ }^{8}$ (ver gráfico 5).

En el área de gobierno también existe una leve diferencia a favor de las mujeres, ya que el 54,8 \% de los cargos son ocupados por ellas.

Grafico 5 - Proporción de empleados de las administraciones públicas locales según áreas de desempeño y género en 17 Municipios de la Provincia de Córdoba. Año 2015.

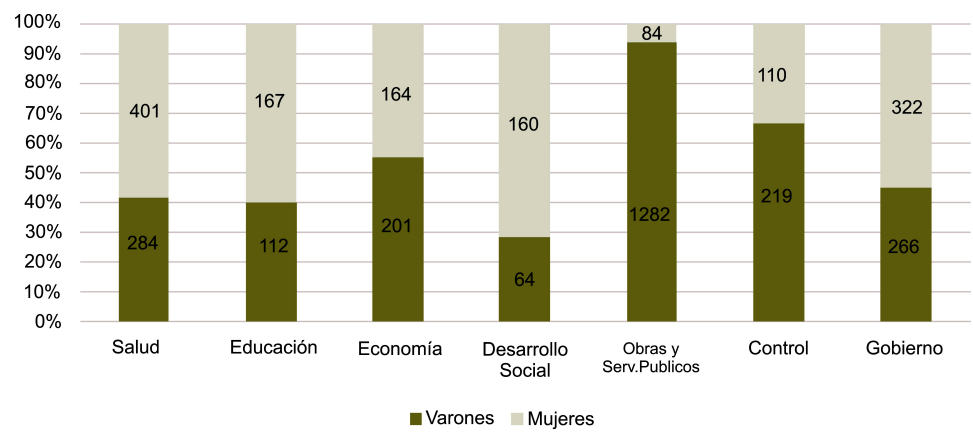

Elaboración propia.

\section{4 - Inequidad en la estabilidad y la formalidad laboral}

La inequidad entre varones y mujeres en el ámbito laboral de las administraciones públicas locales no sólo se relaciona con la

\footnotetext{
${ }^{8}$ Según lo informado por el Ministerio de Trabajo de Argentina (ver http:// www.trabajo.gov.ar/downloads/cegiot/140703_brochure.pdf) en relación con el trabajo no remunerativo y uso del tiempo al año 2013, las mujeres dedicaban en promedio 3 horas diarias más que los hombres en estas actividades. Además este organismo explica que en el mercado de trabajo las ocupaciones en las que mayoritariamente se desempeñan las mujeres se asocian al rol tradicional de ama de casa, razón por la cual se ocupan en puestos asociados al cuidado tales como los de enfermeras, maestras, empleadas domésticas, niñeras, cuidado de enfermos y mayores, etc.
} 
posibilidad de asumir roles de liderazgo y toma de decisiones, sino también con la estabilidad y la formalidad de la relación laboral. Las mujeres representan, como se indicó en párrafos precedentes, un $43,3 \%$ de la planta permanente de los municipios, sin embargo representan un $51,9 \%$ de las personas que prestan servicios mediante monotributo 9 y un $50,8 \%$ de los becarios y/o pasantes (ver gráfico 6), lo que indica que se encuentran en situación de precariedad e inestabilidad laboral. A lo que cabe agregar que sólo un $36,6 \%$ de las mujeres se encuentran en planta permanente ${ }^{10}$.

\section{Gráfico 6 - Proporción de empleados según formalidad laboral y género en 17 Municipios de la Provincia de Córdoba. Año 2015.}

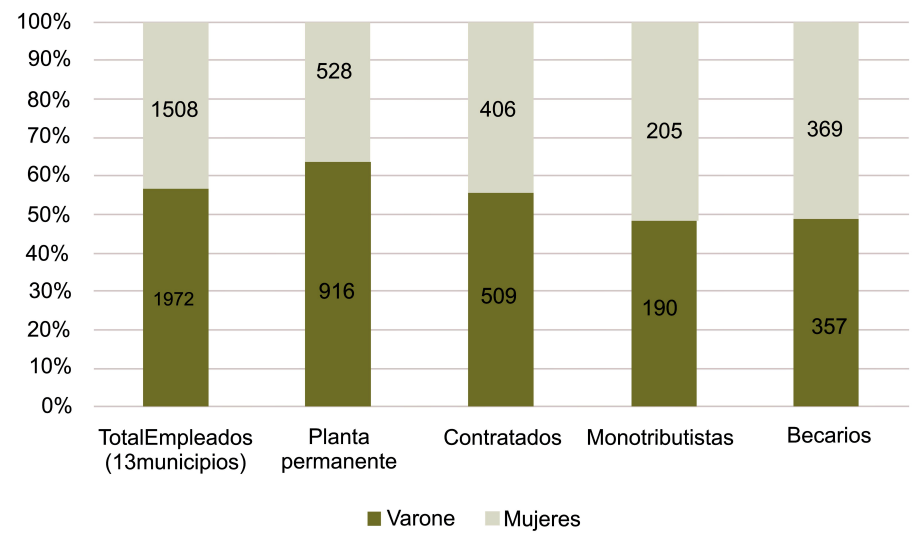

Elaboración propia.

\footnotetext{
${ }^{9}$ Cabe aclarar que las personas que prestan servicios como monotributistas, son entendidas como terceros que prestan servicios profesionales al municipio, y no se encuentran vinculados con éste en una relación de dependencia laboral.

${ }^{10}$ Es importante resaltar que las personas de planta permanente gozan de estabilidad laboral absoluta o propia, es decir, que sólo pueden ser despedidas con justa causa. Los contratados tienen una relación temporal con el empleador y los monotributistas son considerados terceros que prestan servicios, lo que implica precariedad e inestabilidad laboral.
} 


\section{5 - Discusión: La paradoja de la cercanía física y el paradigma de autogobierno frente a baja participación política y segregación ocupacional de las mujeres}

En los últimos años se ha producido una revalorización de las administraciones públicas locales para la calidad de la democracia y para el desarrollo. En este sentido, los municipios son fundamentales para la democracia ya que la organización y la participación ciudadana en la gestión de los asuntos públicos se construye desde el nivel local. En estas instituciones públicas la cercanía entre lo netamente institucional y de gobierno, y lo típicamente ciudadano, comunitario o corporativo (Escobar y Solari, 1996: 109), construye ciudadanía.

Cabe destacar además que los municipios son entendidos como sumamente importantes por los mismos ciudadanos, ya que su accionar incide directamente en sus vidas, especialmente cuando estas unidades políticas son las que entregan los servicios públicos (PNUD, 2010: 2). Además, estas instituciones son concebidas como más accesibles al ciudadano, por la cercanía, sin embargo, parecen no reconocer la importancia de la inclusión y la diversidad, y con ello el fomento de un significado de democracia que reconozca conceptos sustantivos y no sólo formales de igualdad ${ }^{11}$, de diversidad y de interculturalidad.

Los movimientos sociales, las investigaciones a nivel regional, las acciones de los Estados han fomentado la feminización

\footnotetext{
${ }^{11}$ La igualdad en términos formales es entendida como no arbitrariedad, y por lo tanto, impide todo trato diferenciados entre los sujetos iguales; en cambio, en términos sustantivos implica comprenderla como no sometimiento de aquellos grupos sociales que históricamente han visto vulnerado sus derechos. La igualdad como no sometimiento es la que justifica la existencia de medidas afirmativas, es decir, de acciones que reconocen las diferencias y la existencia de grupos sociales que por sus características particulares (género, raza, etnia, etc.) no gozan de reales oportunidades de ejercicio de sus derechos humanos fundamentales.
} 
de la política en los espacios macro, pero no han realizado un esfuerzo semejante en las administraciones locales, que como organizaciones básicas de la administración del estado, y por lo tanto, como organizaciones donde las relaciones del poder público con los gobernados son más directas y se tiene acceso más sencillo a las decisiones de dirección o gobierno, se constituyen en órganos fundamentales para el fomento de la participación ciudadana, y por ende, en constructores de ciudadanía.

La proximidad de los gobiernos locales a la ciudadanía permite a ésta debatir sobre sus intereses, realizar propuestas e influir en la definición de los programas de acción del municipio, ya que los municipios son la administración más cercana a los problemas, inquietudes y modos de vida de los ciudadanos. Las administraciones públicas locales son por tanto cauces inmediatos de participación ciudadana en los asuntos públicos.

En esta cercanía física entre administrado y administración, radica el valor esencial de los gobiernos locales en la construcción de democracia, sin embargo, los casos estudiados ponen de manifiesto que esta proximidad, no identifica, no comprende, ni problematiza la diversidad y las inequidades de género.

Los datos obtenidos evidencian claras inequidades de género no sólo en la participación política sino también en los espacios de liderazgo y toma de decisiones; en la estabilidad y formalidad laboral. Las administraciones públicas locales en análisis se presentan como instituciones patriarcales con marcados territorios masculinos y femeninos, constituyéndose en instituciones productoras y reproductoras de valores, creencias y prácticas androcéntricas.

En definitiva, la proximidad de los municipios produce la paradoja de alejar a la mujer de la participación política, de espacios de poder y de toma de decisiones, de asignarle territorios prefijados, y de imponerle reglas de precariedad e inestabilidad laboral, al asumir los estereotipos de género instaurados social y culturalmente. La proximidad de las administraciones locales con el ciudadano, ha marcado un proceso de instauración de cultura organizacional patriarcal, produciendo inequidades que debilitan 
la ciudadanía de las mujeres, y las relevan al espacio privado o a espacios desjerarquizados.

\section{6 - Conclusiones}

Ante todo resulta indispensable resaltar que las conclusiones del presente estudio revisten el carácter de hipótesis para ser contrastadas en posteriores estudios de casos.

La presencia de mujeres en el mercado laboral se ha incrementadonotablementeen lasúltimas décadas, y los municipios como sujetos empleadores no han estado exentos de esta realidad. De todas maneras, en el ámbito de las administraciones locales, se observan inequidades de género, tales como baja participación política, especialmente en la esfera del Poder Ejecutivo, y segregación ocupacional tanto vertical como horizontal.

La participación de las mujeres en el mercado laboral proporcionado por los gobiernos locales ha alcanzado una cierta paridad con la participación de los varones, sin embargo, este aumento cuantitativo se ve acompañado por techos ${ }^{12}$ y muros de cristal $^{13}$ que establecen inequidades en la participación política, en la ocupación de cargos jerárquicos y de toma de decisiones

\footnotetext{
${ }^{12}$ Techo de cristal se relaciona con la segregación ocupacional vertical, y hace referencia a "creencias y estereotipos, procedimientos, estructuras, relaciones de poder, etc., que obstaculizan el acceso de las mujeres a los puestos de decisión y el desarrollo de sus potencialidades" (Roldán García, Leyra Fatou y Contreras Martínez, 2012: 46), es decir, a la dificultad de las mujeres de acceder a puestos jerárquicos y de mayor responsabilidad y remuneración.

${ }^{13}$ Hablar de muros de cristal, implica hacer referencia a la segregación ocupacional horizontal, específicamente a la "sobrerrepresentación de mujeres en determinados sectores económicos y categorías profesionales" (Roldán García, Leyra Fatou y Contreras Martínez, 2012: 45). Así las mujeres se concentran en los sectores de comercio, de servicios y tareas de cuidado y los varones en la industria y el transporte.
} 
por parte de las mujeres, y le imponen a éstas precariedad e inestabilidad laboral.

La participación política de las mujeres como cabezas del Poder Ejecutivo municipal es escasa. Además parece no presentar un futuro alentador, ya que las últimas elecciones celebradas en los municipios en análisis ponen de manifiesto la existencia de un territorio masculino, dado que la gran mayoría de los candidatos para ocupar el cargo de intendente fueron varones ${ }^{14}$.

La participación en el ámbito del Poder Legislativo local, es decir, en los Concejos Deliberantes, y en los órganos colegiados de control externo muestra mayor paridad, de manera, que puede afirmarse que las acciones afirmativas han fomentado la participación política en los espacios colegiados de deliberación. No obstante, cabe destacar que la mayor equidad observada en estos órganos parece depender casi exclusivamente del efecto proporcionado por las acciones positivas, y no por la existencia de cambios sociales y culturales, o por la modificación de la cultura organizacional patriarcal que parece caracterizar a los gobiernos locales.

Además de la inequidades en la participación política, también pudo comprobarse la existencia de segregación ocupacional, tanto vertical como horizontal.

La segregación ocupacional se caracteriza por negar la participación de las mujeres en roles de liderazgo y toma de decisiones, $\mathrm{y}$ en atribuirles territorios vinculados con la organización social del cuidado.

Las inequidades por género también se observan en la estabilidad y formalidad laboral, ya que las mujeres prestan sus labores en condiciones de inestabilidad y precariedad laboral, al vincularse con las administraciones públicas locales por medio de contratos temporales, locaciones de servicios a través del régimen tributario de monotributistas o simplemente mediante becas o pasantías.

14 Cabe recordar que de 60 candidatos a intendentes, sólo 3 fueron mujeres. 
La persistencia de estas inequidades vulnera el ejercicio real de derechos fundamentales de las mujeres y afecta la calidad de su ciudadanía y por lo tanto, la legitimidad de la democracia.

Las administraciones públicas locales tienen la importante función de fomentar la participación social y el desarrollo de libertades individuales, por ser las instituciones de gobierno más cercanas a los intereses y problemas de los ciudadanos; sin embargo, la presencia en su interior de patrones estereotipados de género, que sobreviven, persisten y se reproducen, impiden alcanzar este rol fundamental, en aras a una democracia de calidad.

Las inequidades de género en el interior de los gobiernos locales ameritan ser diagnosticadas y analizadas, a fin de poner en marcha planes y programas que trabajen en la inclusión, la diversidad y la equidad de género.

Resulta indispensable la existencia de culturas organizacionales sensibles al género en las administraciones públicas locales, para que la participación política y en roles de liderazgo y toma de decisiones por parte de mujeres se convierta en realidad.

\section{7 - Bibliografía}

ABRAMO, L.; VALENZUELA, M. Inserción laboral y brechas de equidad de género en América Latina. En ABRAMO Editora, Trabajo decente y equidad de Género en América Latina. Ginebra: OIT, 2006.

ARCHENTI, N.; ALBAINE, L. Las mujeres en los gobiernos locales. Argentina, 2007-2011. En Revista SAAP, Volumen, 6, N. 2, noviembre 2012, 227-247.

BARRANCOS, D. Mujeres en la sociedad argentina. Una historia de cinco siglos. Buenos Aires: Sudamericana, 2007.

BURIJOVICH, J.; PAUTASSI, L. “Calidad del empleo y calidad 
de la atención en la salud en Córdoba, Argentina. Aportes para políticas laborales más equitativas", Serie Mujer y Desarrollo 60. Unidad Mujer y Desarrollo. Proyecto CEPAL/ GTZ "Políticas laborales con enfoque de género". Santiago de Chile: Naciones Unidas, 2005.

BUVINIC, M.; ROZA V. La mujer, la política y el futuro democrático de América Latina. Washington D.C.: BID, 2004. Disponible en: http://genero.ife.org.mx/docs_informes/02_ MujerPoliticayFuturodeAL.pdf.

CORONA GODÍNEZ, M.; CORREA DE LA TORRE, L., ESPINOSA CALDERÓN, M. Y PEDRAZA DOMÍNGUEZ, M. Cultura institucional y equidad de género en las Administración Pública. México: Instituto Nacional de Mujeres, 2002.

ESCOBAR, S.; SOLARIA, R. El municipio y la democracia moderna. En Nueva Sociedad, N. 142, Marzo-Abril 1996, 108-115.

FAMÁ, M. V. Efectividad de la legislación argentina en materia de violencia doméstica: hacia una mirada integral e interdisciplinaria. En Haydée Birgin y Natalia Gherardi (coord.), Reflexiones jurídicas desde la perspectiva de género, Género, derechos y justicia, tomo 7, México, 2011, 1-101.

FERNÁNDEZ PONCELA, A. Mujeres y política en América Latina: dificultades y aceptación social. En revista Nueva Época, año 19, N. 51, mayo- agosto, 2006, 117-143.

KRIEGER, M. Sociología de las organizaciones: una introducción al comportamiento organizacional, Buenos Aires: Pearson Education, 2001.

LEVÍN, S., disertación “Género y Ciudadanía activa: del derecho a la igualdad a las políticas de equidad".

LUCAS MARÍN, A.; GARCÍA RUIZ, P. Sociología de las organizaciones. México: Mc Graw Hill, 2005.

OCDE, Women, Government and Policy Making in OECD countries: Fostering Diversity for Inclusive Growth, OECD, 2014. 
Disponible en www.oecd.org/gov/women-government-andpolicymaking.htm.

PAUTASSI, L. Equidad de género y calidad en el empleo: las trabajadores y los trabajadores en salud en Argentina. Mujer y Desarrollo 30. Unidad Mujer y Desarrollo. Proyecto CEPAL/ GTZ “Institucionalización del enfoque de género en la CEPAL y en Ministerios Sectoriales", Santiago de Chile: Naciones Unidas. Santiago de Chile, 2001.

PNUD, Igualdad de Género en la Administración Pública, Nueva York: PNUD, 2014. Disponible en http://www.undp.org/content/ dam/undp/library/Democratic\%20Governance/Public\%20 Administration/GEPA_report_SP_Web.pdf

PNUD Pacífico Asiático. Women's Representation in Local Government in Asia-Pacific: Status Report. PNUD, 2010. Disponible en http://www.capwip.org/readingroom/TopotheShelf. Newsfeeds/2010/Women's\%20Particiipation \%20in \%20 Local\%20Government-Asia\%20Pacific\%20(2010).pdf.

PNUD Argentina, 2011, "Aportes para el desarrollo humano en Argentina 2011". Buenos Aires. Disponible en http://www. unfpaargentina.com.ar/sitio/archivos/aportesdesarrollo.pdf

RODRÍGUEZ ENRIQUEZ, C.; PAUTASSI, L. La organización social del cuidado de niños y niñas. Elementos para la construcción de una agenda de cuidados en Argentina, Buenos Aires: ELA, 2014.

ROJO BRIZUELA, S.; TUMINI, L. “Inequidades de género en el mercado de trabajo de la Argentina: las brechas salariales". En Revista de Trabajo. Año 4, N. 6. Agosto diciembre, 2008, pp. 53 a 70.

ROLDÁN GARCÍA, E.; LEYRA FATOU, B.; CONTRERAS MARTINEZ, L. Segregación laboral y techo de cristal en trabajo social: análisis del caso español. En Portularia, Vol. XII, N. 2, diciembre 2012, 43-56. 